\title{
Optimal Operation of a Residential Energy Hub
}

\author{
Z. Rasouli Dogaheh, V. Puig
}

\begin{abstract}
In this paper, the performance of smart grids is optimized in relation with residential energy centers equipping with solar photo-voltaic (PV) units. In this regard, two optimization were be done on energy consumption and price. The results obtained from this study can be used by three groups of external consumers, environmental experts and energy suppliers. Big home appliances consume large part of household energies. With the use of a smart control tool, consumers can program home appliances daily or weekly to pay less by using them in non-peak load time. Hub energy is a concept that has been considered in energy systems mixed with multiple energy carriers. A hub is determined as the locus of activity of system. Certainly, a hub is energy core, in which all activities associated with a system including generation, storage and consumption of energy in applied equipment are determined. In this research, YALMIP toolbox in MATLAB software is used for optimization of energy consumption with the objective of reduction of costs created by fossil fuels with regarding generation ability of a PV generation unit. Using this toolbox, right time to turn each appliance on is specified due to the practical limitations of the appliances and the maximum possible application of PV unit as clean energy generation is done.
\end{abstract}

\section{INTRODUCTION}

Due to lack of energy resources and high costs of production and distribution of energy, people have been always tended to optimize energy consumption, so that they could pay the lowest cost at the same time by using all needed equipment consuming energy. Consumption optimization is in benefit of consumer not only economically, but also it is useful for production units and the environment. Smart grids could be a solution to this problem and implementing these grids can be costly at the beginning; although it can reduce lots of economic costs and environmental pollution in long-term. Smart grids can use local renewable energies like wind and solar energy to solve environmental problems, increase reliability of equipment and system and reduce the costs of infrastructure. The smart grids connected to household grids allow the consumer of electric products, grids and services to act in integrated way as much as possible. Development of smart grids can play key role in reduction of costs related to energy. In this regard, the way of matching the consumptive equipment has become very important. In this study, two methods are used to optimize performance of smart grids in relation with residential energy centers of PV units [1].

Depending on end-user choice, different objective functions can be adopted to solve the optimization problem associated

Z. Rasouli Dogaheh is with the Institute of Robotics of Universitat Politecnica de Catalunya,Campus Diagonal Sud ,Carrer de Pau Gargallo,14, CO 08028 Barcelona Spain(phone: +34 93401 58 80; fax: +34 9340158 81; e-mail: zrasouli@iri.upc.edu). to the optimal management of a residential energy hub. This includes the minimization of the customer's total energy costs, total energy consumption, peak load, emissions, and/or any combination of these over the scheduling horizon are considered here as possible objective functions for the optimization model The customer's total energy costs represent the cost of electricity consumption, the revenue from selling stored/produced electricity to the power grid, and the cost of gas consumption. Total energy consumption of the hub consists of the energy consumption of electrical devices, the electrical energy injected to the grid from stored/produced electricity, and the gas consumption.

In the paper, an optimal operation scheme that uses an objective function for minimization of peak load is formulated based on total electricity demand of the energy hub at each time interval to reduce it.

The structure of the reminder of the paper is as follows: Section II introduced the residential energy hub concept. Section III presents the mathematical model used for control. Section IV describes the proposed optimal operation algorithm. Section V presents simulation results that show the effectiveness of the proposed approach. Finally, Section VI summarizes the main conclusions.

\section{RESIDENTIAL ENERGY HUB CONCEPT}

Energy hub is a concept that has been recently presented in mixed energy systems with multiple energy carriers. A hub is determined as system activity center. Certainly, energy hub is a center, in which all activities related to a system including generation, storage and consumption of energy in applied equipment are determined.

Big home appliances consume large part of household energies and just some of them can have less effect on increasing costs and generation of greenhouse gases for the consumers. The use of a smart control tool enable consumers enable to program home appliances daily or weekly reducing cost moving the consume to the non-peak load time. Moreover, home appliances can be controlled by using of household network systems and remote control could be used to activate them. These systems have usually several specific controls, which are turned on and off through connecting the appliances to electrical socket and home control center. As a result, the users can control different programs and events and implementation of a decision making in central control of household appliances. In this field, a smart decision making core is considered here that can plan the use of home

V. Puig. is with the Institute of Robotics of Universitat Politecnica de Catalunya,Campus Diagonal Sud ,Carrer de Pau Gargallo,14, CO 08028 Barcelona Spain (e-mail: vicenc.puig@upc.edu). 
appliances optimally, so that energy costs could be declined as much as possible. The smart core is inseparable part of an energy management system (EMS), which is modeled based on mathematical equations in [2]. In Fig. 1, full view of the use of an energy hub in presence of different home appliances including energy saver system (e.g. battery), energy generation systems (e.g. PV solar energy and wind power) and two-way communicative links among the components could be observed. The proposed mathematical model and also the controlling method of using appliances are existed in central hub controller. The controller using mathematical model of each element in the hub, setting of the parameters and other external information like users' needs in consuming time try to obtain optimal time of using appliances [2]. This issue is illustrated in Fig. 2. Database of the device includes all technical information of components (e.g. power rate, storage and generation rate) and external information include information of cost, weather prediction, solar radiation and prediction of greenhouse gas $\mathrm{CO}_{2}$ generation.

The horizon of programming and duration of each time period in optimization models could be different depending on type of hub and energy activities in the locus of control.

Now, a short description of each determinant factor to implement optimization of a residential energy hub is presented [3].

\section{II.1Demand of user}

Executive models of household hub energy should be prior for the demand and need of user and the executive orders should be sufficiently simple and executable for the consumer. The model should include common behavior of user (e.g. regulating the room temperature or time of using the appliances). Even at the time that user tends to have most changes for a component of appliances; the model should be able to implement this order.

\section{II.2Daily energy consumption}

In residential places, presence of individuals at home has significant effect on energy consumption pattern. Moreover, the consumption pattern in every house varies due to season and days of week and weekend holidays. In order to consider effect of occupation of house on energy consumption pattern, the term "daily energy consumption" is introduced. This term shows the hourly activity of energy consumption in a programmable area. To determine a reasonable value of residential level of energy center, the historical data of energy consumption presented by smart measurement instrument embedded in each house could be used. Hence, the previous measurement data of weeks and months and years can be used to predict energy consumption in special day and as a result of producing residential load profile. The load profile can be used to obtain an option for daily energy consumption of a house hourly Fig. 3.

\section{II.3 Cost of energy}

Electricity and natural gas pricing is important for this section. The main aim by dynamic pricing is to encourage reduction of energy consumption during peak time of consumption. Fixed-rate plan (FRP), time-of-use (TOU), are two types of pricing schemes available to electricity

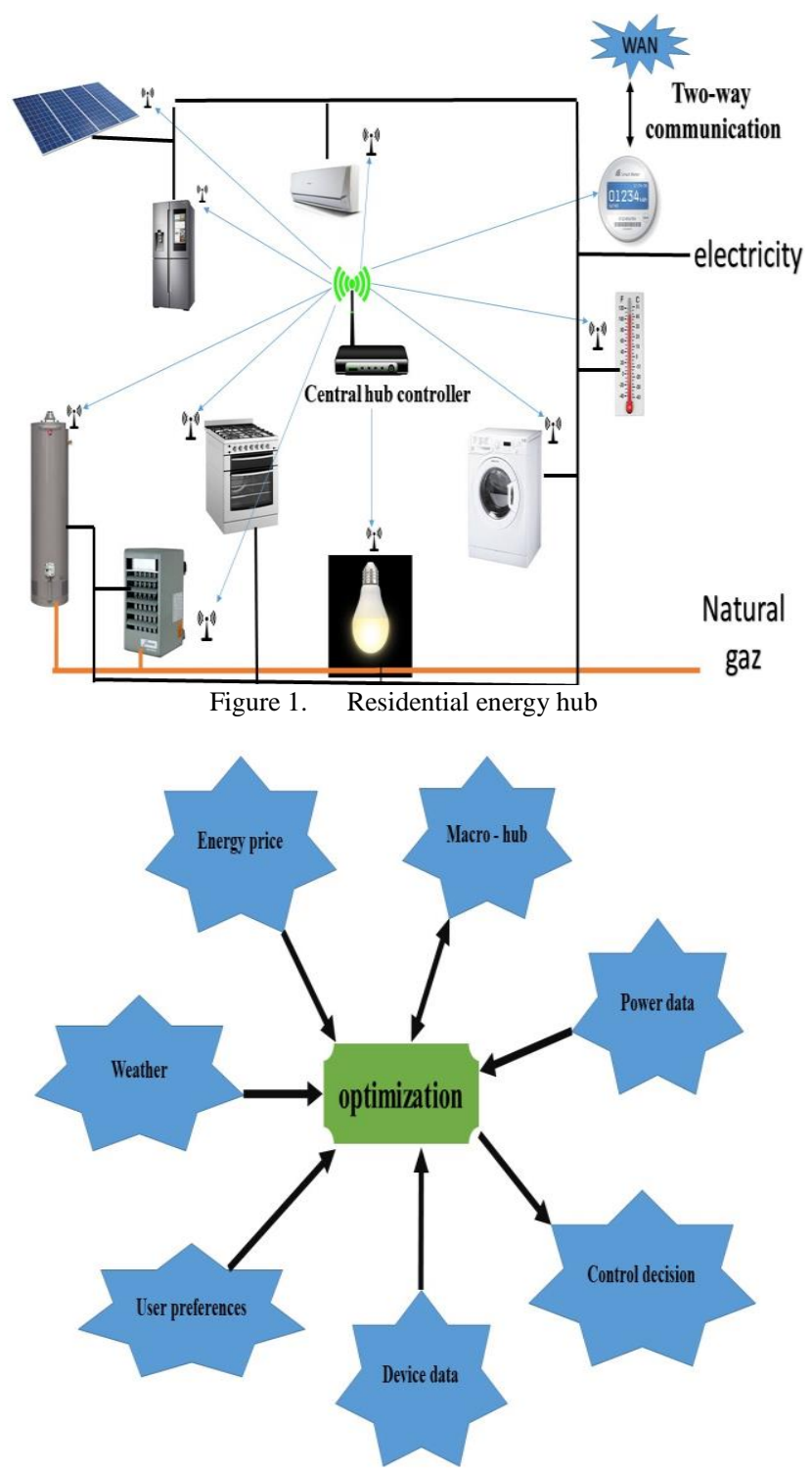

Figure 2. View of central hub controller

customers in various jurisdictions. Natural gas rates for residential customers are usually FRP, which include transportation, storage, and delivery charges beside the commodity charges [4].

\section{MATHEMATICAL MODEL OF ENERGY HUB}

In order to formulate the optimization problem associated to the optimal control of the residual energy hub, the mathematical models of the different components are introduced.

\section{III.1 Fridge}

The model of fridge considering the power and temperature that is suitable for equipment and established by customer's preferences is given by

$$
\theta_{f r}(t)=\theta_{f r}(t-1)+v\left[\psi_{f r} C_{f r}(t)-\mathrm{K}_{f r} s_{f r}(t)+\mathrm{H}_{f r}\right], \forall t \in T
$$


where $\theta_{f(t)}(t)$ corresponds to fridge inside temperature. $\mathrm{v}$ is the sampling time. $C_{f r}(t)$ is the consumption of the fridge, and $s_{f r}(t)$ is the on/off state of fridge. $H_{f r}$ is the cooling and warming effect of the daily consumption $\left({ }^{\circ} \mathrm{C}\right) . \psi_{f r}$ is the cooling and warming effect when the fridge is off $\left({ }^{\circ} \mathrm{C}\right)$

$$
\psi_{f r}=\frac{\triangle \theta_{f r}}{\triangle t}
$$

$K_{f r}$ cooling and warming effect when fridge is on $\left({ }^{\circ} \mathrm{C}\right)$

$$
K_{f r}=\frac{\triangle \theta_{f r}}{\Delta t}+\psi_{f r}
$$

\section{2 Air condition and heater}

Similarly, the air condition (AC) and heater (HT) system models denoted in the following as $(i=a c, h t)$ are modelled as follows

$$
\begin{gathered}
S_{a c}(t)+S_{h t}(t) \leq 1, \forall t \in T_{i} \\
\theta_{\text {in }}(t)=\theta_{\text {in }}(t-1)+v\left[\begin{array}{l}
\psi_{a c} C(t)-K_{a c} s_{a c}(t) \\
+\mathrm{N}_{a c}\left(\Phi_{\text {out }}(t)-\theta_{\text {in }}(t)\right)
\end{array}\right], \forall t \in T \\
\theta_{\text {in }}(t)=\theta_{\text {in }}(t-1)+v\left[\begin{array}{l}
\psi_{h t} C(t)-K_{h t} s_{h t}(t) \\
-\mathrm{N}_{h t}\left(\theta_{\text {in }}(t)-\Phi_{\text {out }}(t)\right)
\end{array}\right], \forall t \in T \\
N_{i}=\frac{\Delta \theta_{\text {in }}}{\left(\theta_{\text {out }}-\theta_{\text {in }}\right)} \times \Delta t
\end{gathered}
$$

$S_{a c}, S_{h t}$ represent the on/off state of AC and HT, respectively. Equation (4) establishes that AC and HT do not work at the same time. Equations (5) and (6) models the dynamics of indoor temperature for both of system AC and HT. $\theta_{i n}(t)$ is the inside home temperature. $\psi_{a c, h t}$ is the cooling and warming effect when air condition and heater are off $\left(\mathrm{C}^{\circ}\right) . C(t)$ is the daily energy consumption, $K_{f r}$ cooling and warming effect when air condition or heating are on $\left(\mathrm{C}^{\circ}\right), s i(t)$ is the on/off state of devices, $N_{i}$ represents the difference between the inside and outside temperature, $\Phi_{\text {out }}$ is forecasted outside temperature. $T_{i}$ is set of period in which device i may operate

\section{III.3. Water heater}

Analogously, the model of the water heater is modelled as follows

$$
\theta_{w h}(t)=\theta_{w h}(t-1)+v\left[K_{w h} s_{h t}(t)-\psi_{w h} W(t)-H_{w h}\right], \forall t \in T
$$

that takes in to account that water heater temperature at a time $t$ as a function of the water temperature at the previous time the average hot water usage and the on/off state of the water heater at time $t$. $\theta_{w h}(t)$ corresponds to the water temperature, $K_{w h}$ represents warming effect when water heating is on $\left(\mathrm{C}^{\circ}\right)$, $\psi_{w h}$ is the cooling effect when the water heating is off $\left({ }^{\circ} \mathrm{C}\right)$, $s_{w h}(t)$ is the on/off state of water heater and $H_{w h}$ cooling and warming effect of the daily consumption $\left({ }^{\circ} \mathrm{C}\right)$

\section{III.4. Washing machine}

The washing machine can be modelled as follows

$$
n_{w m}(t)-m_{w m}(t)=s_{w m}(t)-s_{w m}(t-1), \forall t \in T_{w m}
$$

Time $t: n_{i}(t)=\left\{\begin{array}{lc}1 & \text { startup } \\ 0 & \text { otherwise }\end{array}\right.$

Time $t: m_{i}(t)=\left\{\begin{array}{l}1 \text { shutdown } \\ 0 \text { otherwise }\end{array}\right.$

$n_{i}(t)+m_{i}(t) \leq 1, \forall t \in T_{i}$

$\sum_{t \in T_{i}} s_{i}(d)=Q_{i}^{r t}, \forall t \in T_{i}$

$\sum_{d=t}^{t+Q_{i}^{m s t}} s_{i}(d) \leq Q_{i}^{m s t}+L\left(1-n_{i}(t)\right) \quad \forall t \in T_{i}$

$\sum_{d=t-U_{i}+1}^{t} n_{i}(t) \leq s_{i}(t) \quad \forall t \in\left[E_{i}+U_{i}+1, L_{i}\right]$

(15)

$\sum_{d=t-D_{i}+1}^{t} n_{i}(t) \leq 1-s_{i}(t) \quad \forall t \in\left[E_{i}+D_{i}+1, L_{i}\right]$

(16)

$n_{i}, m_{i}$ are binary variables representing start up and shut down of washing machine.

In this model, in addition to the time periods over which this device can be in operation, which are specified by the customer's settings, additional constraints on the required operation time $\left(Q^{r t}\right)$, maximum successive operation time $\left(Q^{m s t}\right)$, minimum up time $\left(U_{i}\right)$, and minimum down time $\left(D_{i}\right)$, earliest operation time $(E i)$, end of operation time $\left(L_{i}\right)$ of these devices are specified by the end-user, and modeled using (13)-(16).

\section{III.5. Energy storage device}

Today most of smart houses are equipped with some of energy storage devices (ESD) same as batteries. It is assumed that the amount of energy charged in to the ESD at each time [5], [6]

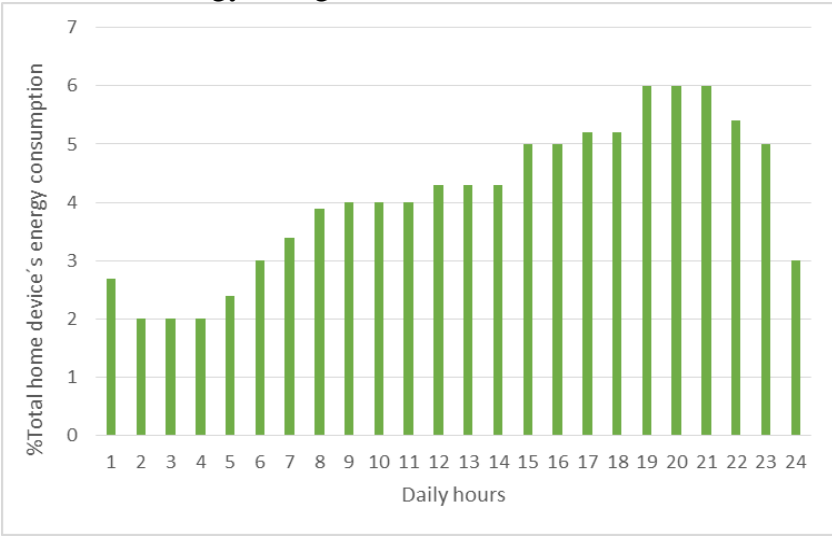

Figure 3. Daily energy consumption 
$e_{\text {esd }}(t)=e_{\text {esd }}(t-1)+$

$v\left[\operatorname{ch}_{e s d}(t)-s_{i}(t) c h_{e s d}^{d}\right]$

$\forall t \in T$

(17)

$$
\begin{array}{lc}
E_{\text {esd }}^{\min } \leq e_{e s d}(t) \leq E_{\text {esd }}^{\max }, & \forall t \in T \\
(18) & \forall t \in T \\
n_{i}(t) \geq s_{i}(t)-s_{i}(t-1), & \forall t \in\left[E_{i}+U_{i}+1, L_{i}\right] \\
\sum_{d=t-U_{i}+1}^{t} n_{i}(t) \leq s_{i}(t) \quad & \forall t \in\left[E_{i}+D_{i}+1, L_{i}\right]
\end{array}
$$

Constraint (17) considers energy charge and discharge and the energy level of the energy storage device at time $t$ up to time $t$-1. Constraint (18) establishes that energy storage level never not come lees than a specified minimum level.

Energy level in ESD at time $t\left(e_{e s d}\right)$, charge power in to the ESD $\left(c h_{e s d}\right)$, discharge power from ESD $\left(c h^{d}{ }_{e s d}\right)$, time duration (v), on/off state of $\operatorname{ESD}\left(s_{i}\right), \mathrm{n}_{\mathrm{i}}$ represent start up time (bainary), minimum up time $(U i)$, and minimum down time $(\mathrm{Di})$, earliest operation time $(\mathrm{Ei})$, end of operation time $(\mathrm{Li})$

\section{III.6. Photo voltaic (PV) system}

The PV system is modelled as follows:

$$
\begin{gathered}
C h_{p v}(t)= \begin{cases}P_{p v}^{c h d} \quad \text { if } P_{p v}(t) \geq P_{p v}^{c h d} \\
P_{p v} \quad \text { if } P_{p v}(t) \leq P_{p v}^{c h d}\end{cases} \\
e_{p v}(t)=e_{p v}(t-1)+v\left[\begin{array}{c}
s_{p c}^{c h d}(t) C h_{p v}(t) \\
-s_{p v}^{d c h}(t) C h_{p v}^{d}
\end{array}\right], \forall t \in T
\end{gathered}
$$

$C h=$ charge, $c h^{d}=$ discharge, $P_{p v}$ represent rated power of photovoltaic $c h_{p v}$ charge power in to the photovoltaic and $c h_{p v}^{d}$ show the discharge from the photo voltaic, $E^{\min }, E^{\max }$ represent respectively minimum energy and maximum energy that photovoltaic can generated.

Equation (22) shows the simulated of constant battery charger operation which used to charge the PV system batteries and assumed the battery voltage is constant during the charging and discharging. Equation (23) considers the effect of the charge and discharge on the battery storage level. Equation (24) does not allow charge of battery go to deep charging and discharging. Equation (25) assumes that the conversion efficiency is complete.

\section{OPTIMAL OPERATION OF ENERGY HUB}

\section{IV.1 Objective function}

Depending on end-user choice, different objective functions can be adopted to solve the optimization problem. Thus minimization of the total energy cost, total energy consumption, peak load are considered here as possible objective functions for the optimization model. The energy management in hub system is multi objective function and this objective include three operational goals with different nature considered and these control objectives are mathematically formulated in term of the following cost function equation.

Form of overall optimization model used in this study for a household energy hub is as follows: optimization includes minimization of overall cost functions as introduced here [7] [8].

$$
\min _{s} \sum_{t}\left(\lambda_{e} l_{d}^{e}+\lambda_{s} l_{d}^{s}+\lambda_{\Delta} l_{d}^{\Delta}\right)
$$

Equation (26) introduces the following objectives

$$
\begin{aligned}
& l_{d}^{e} \triangleq W_{e} u_{d} \\
& l_{d}^{s} \triangleq \xi_{d}^{T} W_{s} \xi_{d} \\
& l_{d}^{\Delta} \triangleq \Delta s_{d}^{T} W_{\Delta u} \Delta s_{d}
\end{aligned}
$$

Where $l_{d}^{e} \in R \geq 0$ represents the economic cost of hub operation including cost of energy production and losses in the transport included $V_{e}$, the cost $l_{d}^{s} \in R \geq 0$ penalizes the amount of energy in the storage threshold. The cost $l_{k}^{\Delta} \in R \geq 0$ represents the penalization of control signal variation $\Delta s_{d} \triangleq s_{d}-s_{d-1}$, which assures a smooth operation and extend components life. Furthermore, $W_{e}, W_{s}, W_{\Delta u}$ are diagonal positive definite matrices that weight each decision variable in their corresponding cost function.

\section{IV.2 Device constraints}

The optimization problem considers the models of the devices presented in Section III as constraints. Additionally, a limitation on maximum consumed power that neve can be higher than determined limit $P_{\max }$ should be satisfied

$$
\sum_{i \in A} P_{i} s_{i}(t) \leq P_{\max }(t), \forall t \in \mathrm{T}
$$

Where $i$ refers to one household appliance.

Moreover, the time period over which device can be in operation is specified by

$$
s_{i}(t)=\left\{\begin{array}{cl}
0 \text { or } 1 & \text { if } t \in T i \\
0 & \text { if } t \notin T i
\end{array}\right\} \forall i \in A
$$

Devices with temperature range such as fridge, air condition, heating, water heater should maintain their respective temperature and stay in constraint temperature that is established by customer preferences. There are two groups: 
one of them for cold weather and another one for warm weather

$$
\Phi_{i}^{\min }(t) \leq \theta_{i}(t) \leq \Phi_{i}^{\max }(t), \forall t \in T_{i}, i \in\{a s, f r, h t, w h\}
$$

$\Phi=$ forecasted temperature in time $t$

$$
\begin{aligned}
& S_{i}(1)=\left\{\begin{array}{l}
1 \text { if } \theta_{i}(0)>\Phi_{i}^{\max }(1), i \in\{a c, f r\} \\
0 \text { if } \theta_{i}(0)<\Phi_{i}^{\min }(1), i \in\{a c . f r\}
\end{array}\right\} \\
& S_{i}(1)=\left\{\begin{array}{l}
0 \text { if } \theta_{i}(0)>\Phi_{i}^{\max }(1), i \in\{h t, w h\} \\
1 \text { if } \theta_{i}(0)<\Phi_{i}^{\min }(1), i \in\{h t, w h\}
\end{array}\right\}
\end{aligned}
$$

Equation (30) and (31) establishes that the device's temperature should be the in range of customer's preference. If the device temperature goes out of the upper/lower limits the device will be on.

\section{SIMULATION}

In this study, YALMIP optimization software is used for purpose of optimal operation of the energy hub with the aim of reducing costs. First, the power related to devices is defined in binary form. It means that each device can be only in two modes on /off and to calculate their consumed power in "on" mode, they are only multiplied in their nominal power [9] [10]. Here, the value 4 refers to 4 devices, for which optimized "on" mode is going to be. The simulation horizon is 48 hours. Control set-points are recalculated every 30 minutes. In the following, the presented results show how using optimization the consumption costs are reduced by using the non-peak hours. For example, the consumption power diagram of one of the high energy consuming devices as the refrigerator is given in Fig. 4. In this plot, the consumed power showing the "on" times of fridge engine is illustrated by blue lines and the temperature inside the refrigerator is assumed to $3-8^{\circ} \mathrm{C}$. The refrigerator consumed power of $450 \mathrm{~W}$ when in "on" mode. Formulation of function of refrigerator is in such manner that when fridge engine is started, the temperature inside the fridge is decreased. Optimization algorithm tends to use lowest "on" mode of fridge to reduce cost [11] [12]. For water heater use constraints for keeping the temperature between $70-76 \mathrm{C}^{\circ}$ when the temperature go up the $70 \mathrm{C}^{\circ}$ water heater was be off and the power consumption will be come down and when temperature be come down the water heater be on and use of power generated for increase the temperature Fig. 5. Air condition use of constraints for keeping the temperature between $16-24 \mathrm{C}^{\circ}$ when we use of this constraint the Air condition motor not be on all of the time because when the temperature is between our preference Air condition fan can be off and not use of power generation with this activity we can to grant the customer's preference and decrease the power consumption Fig. 6.We put constraint for activity of photo voltaic when we have most of sun radiation in a day Fig. 8, and for battery is be charge when photo voltaic generated power and discharge battery when the photo voltaic could not generation power Fig. 9. With these constraints we can hold operation of devices on constant bounds power and we can satisfy costumer's preferences and reducing energy consumption for example for washing machine operation be programed for time that photovoltaic generate power is maximum. See Figs. 7 and 8 [13]. Fig. 9 shows the stored energy in the battery.

\section{CONCLUSIONS}

In this study, a multipurpose energy management system is used to optimize energy hub performance to reduce costs during a day. In the proposed algorithm, optimization is performed according to limitations of main energy consuming machines like fridge, cooler, washing machine. Here, due to recursivity of thermal limitations of resources and the standby time desired by user for each of them, nonlinear optimization is used. Energy consumption optimization with the purpose of reduction of costs of using fossil fuels is done with regard to generation power of a PV generation unit. This study has been able to specify favorable time for turning on each household appliance due to practical limitations of them and to use PV unit as generator of clean energy as much as possible. This the wide range can lead to reduction of electric power generation costs. We can do this process for more time because optimization in long time can be increase the cost better than the short time.

\section{ACKNOWLEDGEMENT}

This work has been partially funded by the Spanish State Research Agency (AEI) and the European Regional Development Fund (ERFD) through the projects DEOCS (ref. MINECO DPI2016-76493) and SCAV (ref. MINECO DPI2017-88403-R).

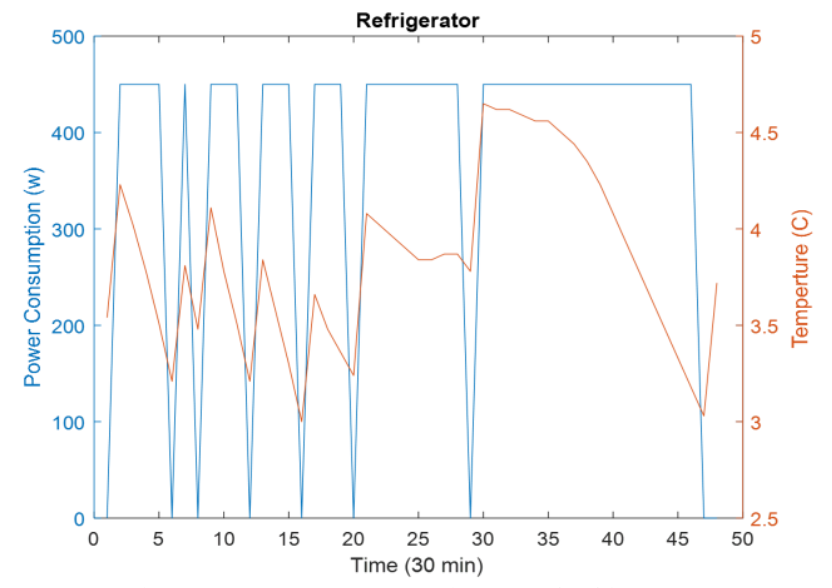

Figure 4. Temperature and power of refrigerator

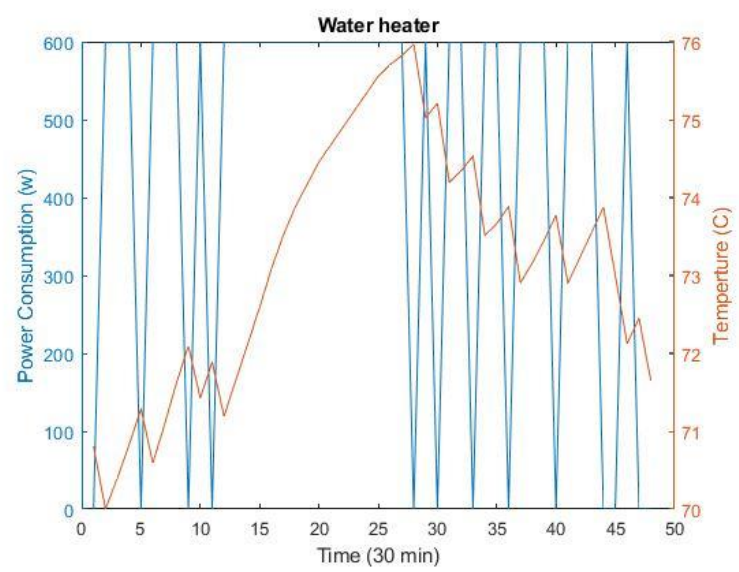

Figure 5. Temperature and power of water heater 


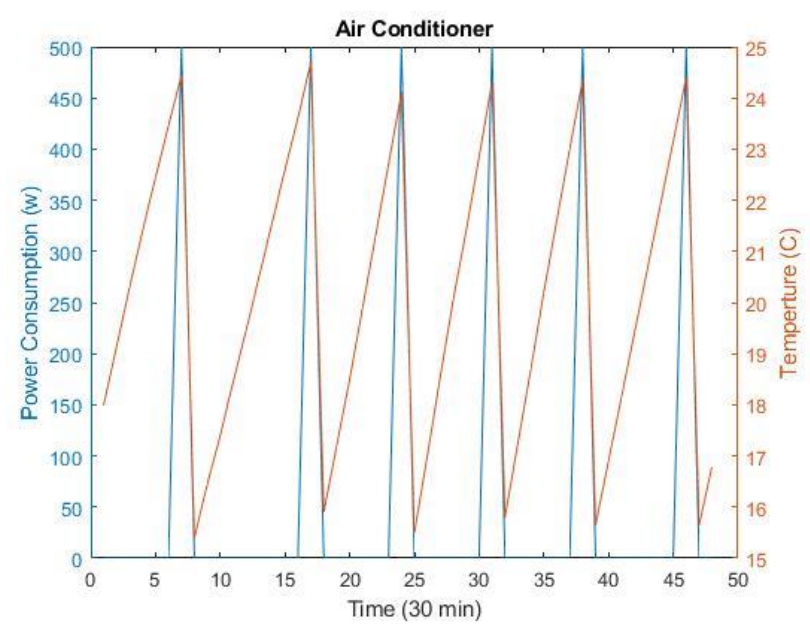

Figure 6. Temperature and power of air condition

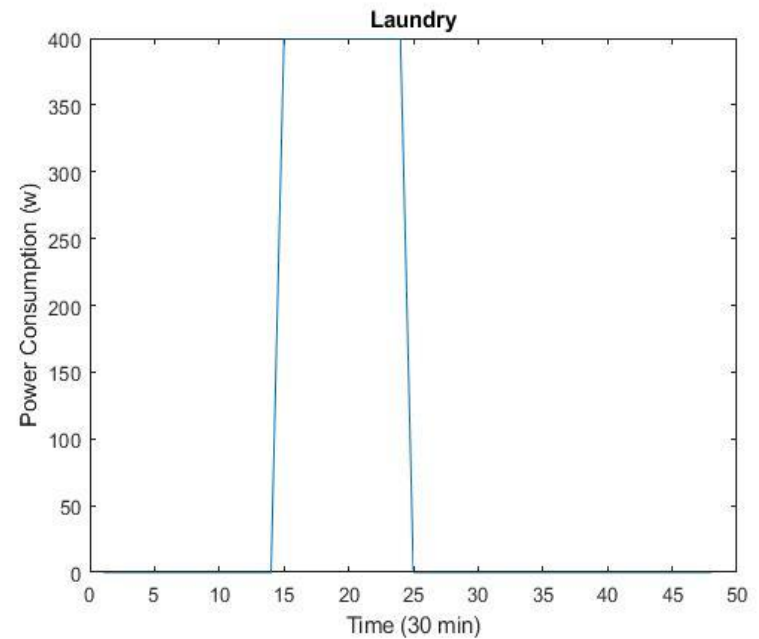

Figure 7. Power of washing machine

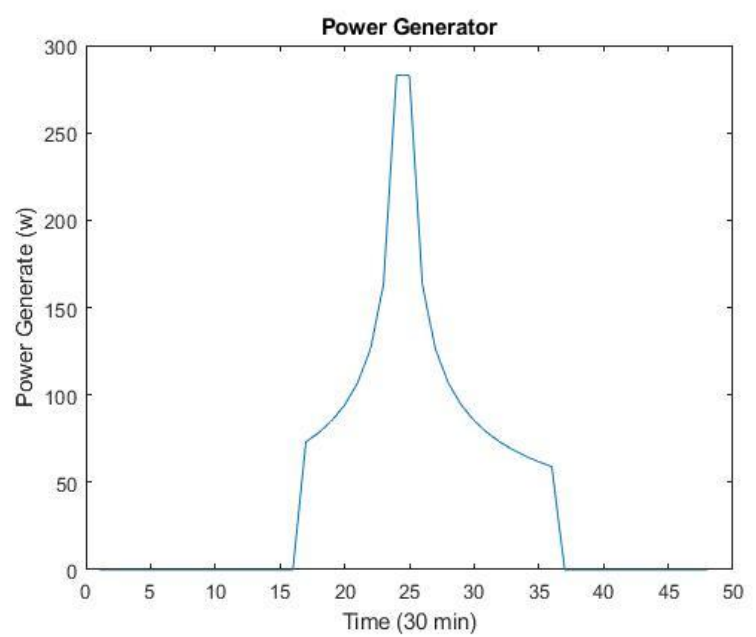

Figure 8. Generation power of solar panel

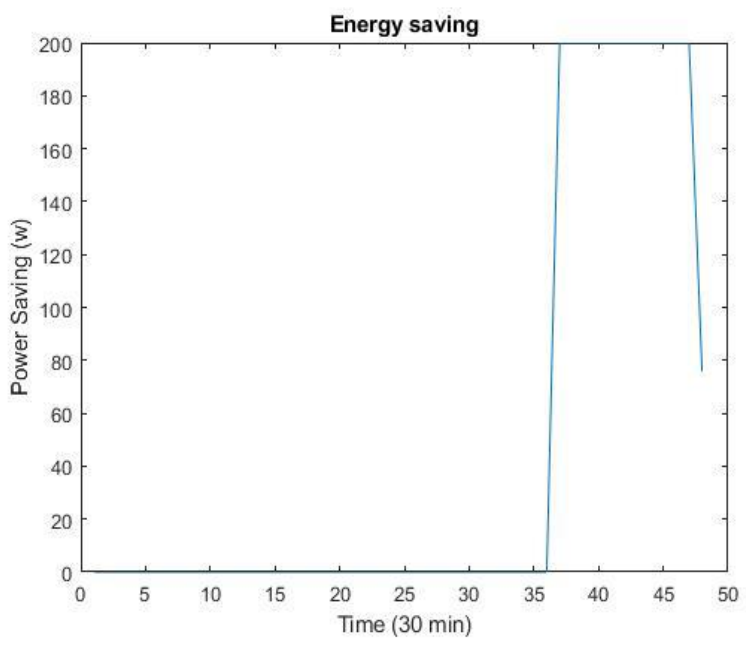

Figure 9. Power stored

\section{REFERENCES}

[1] Ppa, N. Thanushkodi, K. (2010). "Improvemed Power Quality Using Photovoltaic Unified Static Compensation Techniques", Asian Power Electronics Journal, Vol. 4 No.2.

[2] Michael Angelo A. Pedrasa, T. D. Spooner, an Iain F. MacGill.(2010) Coordinated Scheduling of Residential Distributed Energy Resources to Optimize Smart Home Energy Services. IEEE Transactions on Smart Grid, Vol. 1, No. 2.

[3] 1- Kuri, B. Li, F. (2005) "Valuing emissions from electricity towards a low carbon economy," in Proc. IEEE PES Gen. Meet, pp. 53-59.E. H. Miller, "A note on reflector arrays (Periodical style-Accepted for publication)," IEEE Trans. Antennas Propagat., to be published.

[4] 21-WBCSD, transforming the market: energy efficiency in buildings, survey report. The World Business Council for Sustainable Development; April 2009

[5] 8- Yoza, A., Yona, A., Senjyu, T., \& Funabashi, T. (2014). Optimal capacity and expansion planning methodology of PV and battery in smart house. Renewable Energy, 69, 25-33M. Young, The Techincal Writers Handbook. Mill Valley, CA: University Science, 1989.

[6] Michael Angelo A. Pedrasa, T. D. Spooner, an Iain F. MacGill.(2010) Coordinated Scheduling of Residential Distributed Energy Resources to Optimize Smart Home Energy Services. IEEE Transactions on Smart Grid, Vol. 1, No. 2.

[7] Levermore GJ. Building energy management systems: applications to lowenergy HVAC and natural ventilation control. 2nd ed.. London: E \& FN Spon; 2000

[8] Shaikh PH, Mohd. Nor NB, Nallagownden P, Elamvazuthi I, Ibrahim T. Robust stochastic control model for energy and comfort management of buildings. Australian J. Basic Appl. Sci. 2013;7(10):137-44.

[9] Y.W.Baiand C.H. Hung,"Remote power on/off control and current measurement for home electric outlets based on a low-power embedded board and zigbee communication," in Proc.IEEE Int. Symp .Consum. Electrom., 2008, pp. 1-4.

[10] D. M. Han and J. H. Lim, "Smart home energy management system using IEEE 802.15. 4 and Zigbee," IEEE Trans. Consum. Electron., vol. 56, no. 3, pp. 1403-1410, 2010.

[11] A. H. Mohsenian-Rad and A. Leon-Garcia, "Optimal residential load control with price prediction in real-time electricity pricing environments,"IEEETrans.SmartGrid,vol.1,no.2,pp.120-133,2010.

[12] B. Jiang and Y. Fei, "Smart home in smart microgrid: A cost-effective energy ecosystem with intelligent hierarchical agents," IEEE Trans. Smart Grid, vol. 6, no. 1, pp. 3-13, Jan. 2015.

[13] G.DelilleandB.Francois,"Areviewofsometechnicalandeconomicfeature s of energy storage technologies for distribution systems integration," Ecol. Eng. Environ. Protect., no. 1, pp. 40-49, 2009

[14] M. McGranaghan and A. Chuang, "Functions of a local controller to coordinate distributed resources in a smart grid," in Proc. IEEE PES Gen. Meeting, Jul. 20-24, 2008, pp. 1-6, [CD-ROM]. 